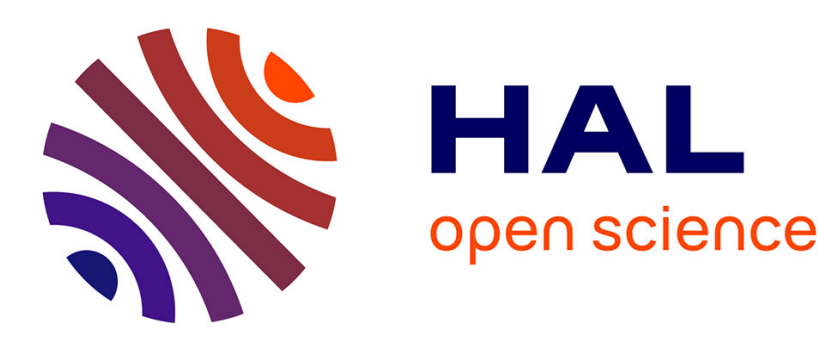

\title{
Laser ablation of graphite with near infrared microsecond pulses
}

\author{
T. Doualle, M. Reymond, Y. Pontillon, L. Gallais
}

\section{To cite this version:}

T. Doualle, M. Reymond, Y. Pontillon, L. Gallais. Laser ablation of graphite with near infrared microsecond pulses. Applied physics. A, Materials science \& processing, 2021, 127 (9), pp.722. 10.1007/s00339-021-04815-z . hal-03466235

\section{HAL Id: hal-03466235 \\ https://hal.science/hal-03466235}

Submitted on 25 Feb 2022

HAL is a multi-disciplinary open access archive for the deposit and dissemination of scientific research documents, whether they are published or not. The documents may come from teaching and research institutions in France or abroad, or from public or private research centers.
L'archive ouverte pluridisciplinaire HAL, est destinée au dépôt et à la diffusion de documents scientifiques de niveau recherche, publiés ou non, émanant des établissements d'enseignement et de recherche français ou étrangers, des laboratoires publics ou privés. 


\section{Laser ablation of graphite with near infrared microsecond pulses}

T. Doualle ${ }^{1, *}$, M. Reymond ${ }^{1,2}$, Y. Pontillon ${ }^{1}$, L. Gallais ${ }^{2}$

${ }^{1}$ CEA, DES, IRESNE, DEC, Cadarache F-13108 Saint-Paul-Lez-Durance, France

${ }^{2}$ Aix Marseille Univ, CNRS, Centrale Marseille, Institut Fresnel, Marseille, France

*email adress : thomas.doualle@cea.fr

Abstract:

Laser processing of polycrystalline porous graphite through micro to millisecond pulses with $1 \mu \mathrm{m}$ wavelength is investigated. The study aims at finding the best compromise between the efficiency of the process (ablation rate) and the quality (reduced heat affected zone) for drilling and cutting applications. Our experimental approach is based on experiments involving a monomode $\mathrm{kW}$ Ytterbium fiber laser $(1080 \mathrm{~nm})$ coupled to a laser scanning system. This system is used for parametric studies on pulse duration, power, repetition rate and scanning speed on samples that are analysed with Scanning Electron Microscopy. To improve the understanding of the underlying physical phenomena and processes involved a Finite Element numerical model is developed, taking into account energy deposition through optical ray tracing, heat transfer, sublimation of the material and crater formation. Based on these experimental and numerical tools we identify some optimum parameters to fabricate high aspect ratio shapes in graphite samples of $1.5 \mathrm{~mm}$ thickness with excellent edge quality and minimal heat-affected-zone. Laser processing under vacuum atmosphere is also studied and exhibit no difference in behaviour compared to ambient atmosphere.

Keywords: Laser ablation, graphite, laser cutting, vacuum, finite element model

\section{Introduction}

Lasers are essential tools for macro and micro-processing for a whole range of materials in scientific research and in different fields of production industry. Processes involving lasers provide a unique 
solution with minimum mechanical and thermal influence on the processed part due to their selective energy control and deposition and allow generally high processing speeds.

For instance, Pulsed Laser Ablation (PLA) is a technique of vast scientific and significant industrial interest because of its many benefits (precision, excellent edge quality and minimal heat affected zone (HAZ)), in a large wide of materials and thus of its potential applications in micromachining (drilling and cutting) ${ }^{1-8}$, deposition of coatings and thin films ${ }^{9-11}$, synthesis of a wide range of nanostructures and nanoparticles or surface patterning ${ }^{12-15}$. The most attractive feature of PLA is the highly localized spatial interaction between the beam and the material, leading to-small feature, precision, excellent edge quality and minimal heat-affected-zone (HAZ) ${ }^{1-7}$. Itcan be usedon very different materials such as metals ${ }^{2,8,9}$, polymers ${ }^{10}$, glasses ${ }^{11}$, oxide ceramics ${ }^{12}$ or semiconductors ${ }^{13}$ -

In this work, we study laser ablation of graphite. Graphite is used in large number of scientific and industrial applications because of some of its peculiar properties: it is extremely resistant to heat, nearly inert in contact with almost any other material, has good thermal and electrical conductivity. Its refractory properties in combination with its mechanical properties make it a material of choice in very demanding applications in the nuclear or aerospace fields and lasers can be used in various ways to process it.

Pulse laser ablation can be used on graphite targets to : evaporate and deposit diamond-like-carbon (DLC) films on many substrates ${ }^{16-22}$ or manufacture wide variety of carbons, such as fullerenes ${ }^{23}$, carbon nanotubes ${ }^{24}$, carbon nanowalls ${ }^{25}$ and graphene ${ }^{26,27}$. It can also be used for the removal of co-deposited layers from graphite plasma limiters in tokamaks ${ }^{28}$. Shirk et al. demonstrated the clean and precise machining capabilities of ultra-short pulsed lasers for highly oriented pyrolytic graphite (HOPG) ${ }^{29}$. Hoffman et al. studied the effect of the laser wavelength and fluence on the ablation of solid carbon surfaces $^{30}$. Many researches have been focused on improving lithium ion battery process: experimental and numerical studies are conducted on laser micro-processing of lithium-ion batteries which are commonly copper as a current collector and graphite as an active electrode material. Laser 
cutting allows an improved quality of cut surface and cutting speed during lithium-ion battery manufacturing processes ${ }^{31-35}$. Laser structuring of electrodes is a promising approach to enhance the high-current capability of lithium-ion batteries by reducing cell internal resistances ${ }^{36}$.

Generally, with PLA approach the quality of the processing result is reduced by thermal damage of the workpiece and therefore the quality is increased with shorter pulse duration: the Heat Affected Zone (HAZ) is reduced, leading to higher accuracy. However, ablation efficiency decreases as well. If high precision is needed, short and ultrashort (femto-, pico- and nanosecond laser) in combination with adequate drilling strategies are applied (such as trepanning). Ultrashort laser pulses even allow less thermal damage and a nearly melt free ablation, if it is operated close to ablation threshold. However, single pulse drilling using milli- and microsecond pulses that can couple few Joules (1000 W in $1 \mathrm{~ms}$ ) per pulse are much more efficient and allow the production of many craters within a short time. The drawback however is the extension of the HAZ, leading to potentially low quality and reproducibility of the craters.

Garnov et al. studied the ablation of graphite with microsecond range laser pulses at a wavelength of $1.06 \mu \mathrm{m}^{37}$. Their experiments demonstrated an increase of one to two order of magnitude in the ablation rate compared to that for nano-, pico- and femtosecond laser ablation. They have shown excellent crater quality comparable with that obtained with shorter laser pulses.

Moreover, over the past several years, the development of high power, single-mode fiber lasers established a new level of beam quality. In comparison with nano-, pico-, and femto-lasers, the peak power of modulated fiber laser pulse is low but its excellent beam quality allows for tight focusing to reach very high power density for drilling and cutting.

In this context, the aim of this work is to investigate microsecond pulses ablation to achieve a compromise between the ablation rate and quality in micro-processing technologies for graphite material. Our approach is based on the one hand on experiments involving a monomode $\mathrm{kW}$ Ytterbium fiber laser, and on the other hand on a numerical model to improve the understanding of the 
underlying physical phenomena and processes involved. These results, obtained on graphite, will be used as a first step towards machining nuclear fuels, such as UO2 or MOX, allowing sample preparation for various applications (annealing tests, mechanical behaviour or thermophysical properties).

In Sec. II, we present the experimental setup and the process parameters which are used to heat up graphite material above sublimation temperature and hence locally ablate material from graphite surface. Section III is dedicated to the description of the model developed to understand the typical crater profiles obtained with our microsecond laser ablation/cutting approach. We particularly describe the calculation method which involves the coupling of different physical effects: ray optics propagation, heat transfer and thermodynamics. The graphite parameters used and their temperature dependence are also described and discussed. Finally, in Sec. IV, we discuss about the results. We firstly describe single-pulse laser ablation and the evolution of the crater dimensions as a function of the laser parameters. To improve the understanding of the experimental results (craters dimensions and morphology), we compare the simulations results to the experimental crater dimensions. Secondly, we describe a laser cutting technique and its performances which could be applied for graphite manufacturing. To finish, we investigate the influence of a vacuum atmosphere on the cutting performances.

\section{Experimental setup and process parameters}

\section{a-Experimental setup}

The experiments were conducted on the EDM-3 graphite from POCO Graphite Inc., which is a polycrystalline graphite produced by sintering. This material is used mainly for its electrical properties, as an electrode for Electrical Discharge Machining (EDM) process. There are different grades of EDM graphite with significant different properties, mainly related to the microstructure. EDM-3 is one of the so-called "Ultrafine" versions, characterized by an average grain size which is less than 5 microns. It has a porosity of about $20 \%$ and it is macroscopically homogeneous with a high degree of isotropy. No specified surface finishing has been done on the samples surfaces. The surface roughness was 
measured to be few microns, using a 3D profilometer (NewView 7300, Zygo). The thicknesses of the samples used for this work vary from 0.5 to $1.5 \mathrm{~mm}$.

For the experiments, an Ytterbium fibre laser (redPOWER Qube $1.5 \mathrm{~kW}$, SPI Lasers), which has a central wavelength of $1080 \mathrm{~nm}$ with a bandwidth $<4 \mathrm{~nm}$, with a maximum output power of $1500 \mathrm{~W}$ is used. A high power laser collimator generates a $13.5 \mathrm{~mm}$ diameter Gaussian beam that is injected in a 2D scanning head composed by two galvanometer mirrors (intelliSCAN 20, ScanLab). A schematic diagram is represented in Figure 1 (a). The laser beam is focused using an F-theta lens with a focal length of $f=$ $255 \mathrm{~mm}$ and the working distance, i.e. the distance between the exit of the focusing lens and the nominal working plane, is $303 \mathrm{~mm}$. In this plane, the laser beam was measured with a beam profiler (Beamage 4M, Gentec) and the diameter at $1 / \mathrm{e}^{2}$ is $40 \mu \mathrm{m}$. The typical image field size is $110 \times 110 \mathrm{~mm}^{2}$. The maximum marking speed of our scanning head is $1 \mathrm{~m} / \mathrm{s}$ with a repeatability $<2 \mu$ rad.
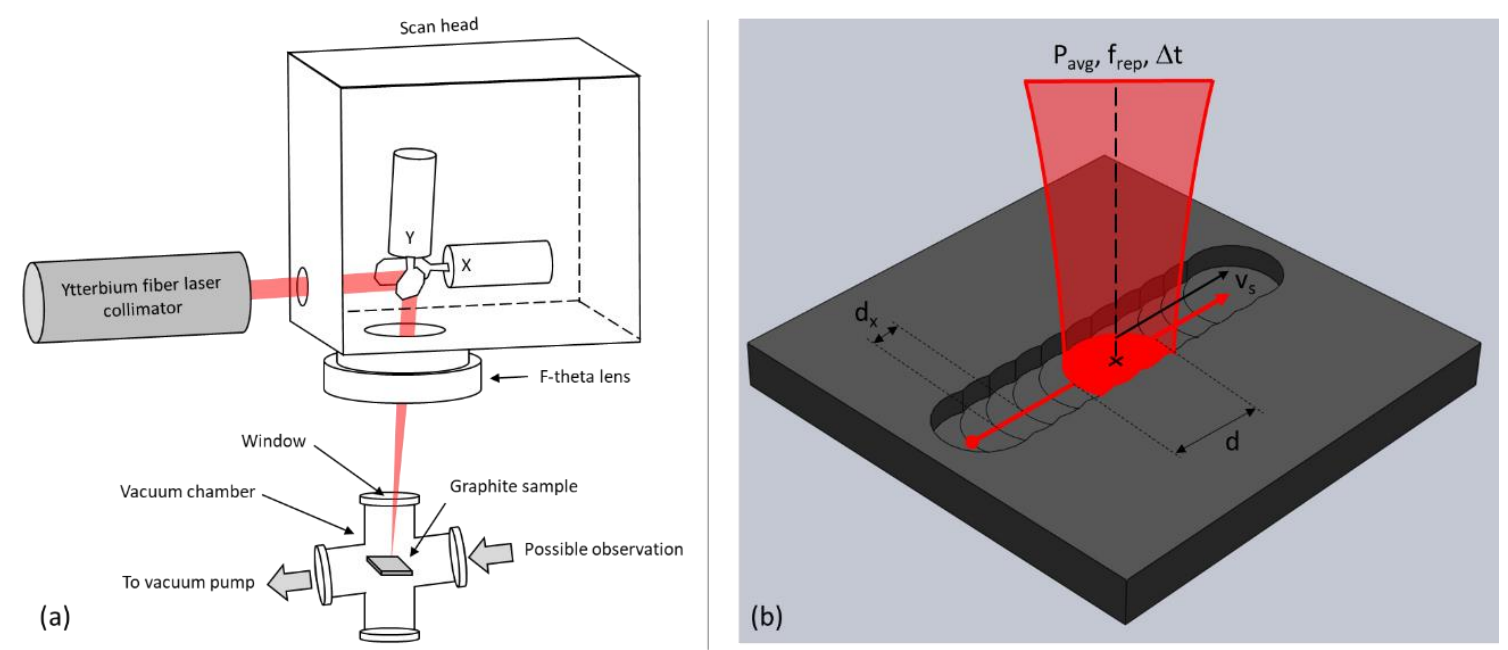

Figure 1 : (a) Schematic diagram of the scan head. (b) Illustration of the process parameters involved during laser processing.

A commercial laser machining software (LaserDesk, Scanlab) is used to control and generate the movements of the mirrors and ensure the synchronization with the laser irradiation. The laser power was calibrated with a power calorimeter (Gentec, UP55C-2.5KW-HD-D0). The experiments present in Sec. IV a, b and c were conducted under air and the graphite sample were placed in a sample holder. 
For the experiments conducted under vacuum atmosphere, presented in Sec. IV d, the laser beam is focused in a vacuum chamber (X40K, Neyco), equipped with a UV fused silica window (WG41050-C, Thorlabs) which has an antireflection coating for the laser wavelength. The vacuum chamber is connected to a vacuum pump and the operating pressure, is close to $10 \mathrm{mbar}$-and. EThe graphite sample is placed at the center of the chamber.

\section{b-Process parameters}

The main process parameters for ablating and cutting graphite sample with pulse laser irradiation are shown schematically in Figure 1 (b).

The laser beam has an average power of $P_{\text {avg }}$ a pulse duration $\Delta t$, a repetition rate $f_{\text {rep }}$, and is focused on a diameter $d$ (gaussian beam, defined at $1 / \mathrm{e}^{2}$ ). It is moved across the graphite surface at the scan speed $v_{s}$ in a unidirectional scan pattern resulting in a distance $d_{x}$ between each pulse:

$$
d_{x}=\frac{v_{s}}{f_{r e p}}
$$

The ablation depth $z_{a b}$ is determined as the height difference between the initial surface and the bottom of the ablated area and the ablated width $w_{a b}$ corresponds to the diameter of the individual hole generated by each pulse.

The cutting laser process involves series of overlapped individual holes. The spot overlap, Soverlap, is important in laser processing because it has an impact on the machining quality. For a homogenously ablated surface, the pulse distance $d_{x}$, calculated with Eq. (1), is set to values smaller than $d$ and the spot overlap is defined as:

$$
S_{\text {overlap }}(\%)=100 \times\left(1-\frac{v_{s}}{f_{\text {rep }} \cdot w_{a b}}\right)
$$

The optimization of $d_{x}$ and $\mathrm{S}_{\text {overlap }}$ is discussed in section IV. 


\section{c-Characterizations}

Regarding sample characterizations, surface observations are carried out employing an optical microscope (Axiotech, Zeiss) and a scanning electron microscope (TM 1000, Hitachi) to investigate the morphology of craters and structures formed and measure their dimensions.

\section{Modeling}

To go further in the investigation and understand the laser ablation mechanisms, simulations are conducted with the commercial software COMSOL which is based on the Finite Element Method. A two dimensional model is applied in our case (axisymmetric). Heat transfer by conduction associated with deformed geometry and ray-tracing modules are employed for the analysis of the thermal effects, material evaporation and laser propagation on the fabricated structures. The objective of the ray tracing approach is to reproduce the beam propagation to understand the particular shape of the experimental craters. In such a numerical model, particularly at high temperature, the input parameters of the simulations are very critical to describe as accurately as possible the laser material interactions, particularly the temperature dependencies. The thermal model and its associated input parameters presented in this paper are based on the model described and validated up to $3800 \mathrm{~K}$ in a previous study ${ }^{38}$. We describe below the different modules of our multi-physics model.

\section{a-Heat transfer in graphite}

The heat transfer model relies on several assumptions. First, the graphite is considered homogenous and isotropic. Second we take into account the heat transfer by conduction combined with thermal radiation to take into account losses at the surface sample (convection is neglected). Third, as the energy is absorbed on the surface, there is no heat source in the material but an incoming heat flux on the boundary. The corresponding non-linear heat transfer equation can be express as:

$$
\rho(T) C(T) \frac{\partial T}{\partial t}-k(T) \Delta T=0
$$


where $\rho$ is the density, $C$ is the specific heat capacity under constant pressure and $k$ is the thermal conductivity which are function of the temperature $T$.

Evaporative cooling is included as a surface boundary condition since it can be a significant heat transport mechanism as the temperature comes closer to the sublimation point. The outgoing heat flux at the boundary can be obtained as ${ }^{38}$ :

$$
\varphi(T)=\frac{d m}{d t d S} \frac{\Delta H_{v}}{R}=\beta \sqrt{\frac{M}{2 \pi R T}} \frac{\Delta H_{v}}{R} p_{0} \exp \left[\frac{\Delta H_{v}}{R}\left(\frac{1}{T_{v}}-\frac{1}{T}\right)\right]
$$

with $M$ being the molar mass of carbon, $R$ the perfect gas constant, $\Delta H_{v}$ the enthalpy of the phase change, $T_{v}$ the temperature of the phase change at ambient pressure $p_{0}$. These parameters are given in Table 1.

\section{b-Deformed geometry}

To simulate the crater formation, we have taken into account in the numerical model the velocity of the evaporation front at the sample surface, given by ${ }^{38},{ }^{39}$ :

$$
v(T)=\beta \sqrt{\frac{M}{2 \pi R T}} \frac{p_{\text {sat }}(T)}{\rho(T)}
$$

To investigate the crater formation dynamics, we have used a moving boundary condition at the sample surface, controlled by the local evaporative velocity, associated with a moving mesh functionality in the 2D numerical model.

\section{c-Optical ray tracing}

The incoming heat flux is deduced from a ray tracing approach. The laser beam is discretized in rays transporting an amount of energy and computed, one by one, through ray propagation and interactions between the material and the geometry. The principle of this technique is quite simple and commonly used ${ }^{40-44}$. A diagram of the calculation method for one time step of our model is given in Figure 2 : 
a) The rays are released from a grid for which we define the initial position, the ray direction vector and the initial intensity (Gaussian distribution). To simulate the interaction with the graphite sample surface, we define a wall (represented by the red boundary in the Figure 2 (a)), which determines the behaviour of the rays when they contact the boundary. At each reflection, the material absorbs an intensity amount (absorptivity) and the remaining intensity is reflected following Snell-Decartes law (specular reflection) or following Lambert's cosine law (diffuse scattering). This process occurs until the complete absorption of the beam or until the ray goes out of the crater.

b) To compute the power deposition, we define the reflection properties, with the absorption coefficient $A$, which gives the deposited power on the boundary.

c) The previously described heat transfer equation (Eq. (3)) is governing the temperature evolution. During the temperature calculation, the crater is formed with the deformation of the geometry calculated from the velocity of the evaporation front (Eq. (5)).

d) At the end of the calculation step, a deformed geometry is obtained which is meshed and used for the next time step calculation.

This procedure is repeated until it satisfies the designated computation time. Typically, the time step is $1 \mu \mathrm{s}$.

\section{d-Graphite parameters}

The different graphite parameters including thermal dependencies are summarized in Table (1).

Table 1 - Parameters for graphite used for our model

\begin{tabular}{|l|l|l|l|}
\hline Symbol & Parameter & Value & Unit \\
\hline $\mathrm{R}$ & Reflection $^{38}$ & $8.5+0.5$ & $\%$ \\
\hline $\mathrm{M}$ & Molar mass & 12 & $\mathrm{~g} / \mathrm{mol}$ \\
\hline $\mathrm{U}_{\mathrm{s}}$ & Latent Heat of sublimation ${ }^{31}$ & $7.18 \times 10^{5}$ & $\mathrm{~J} / \mathrm{mol}$ \\
\hline $\mathrm{T}_{\mathrm{s}}$ & Temperature of sublimation ${ }^{31}$ & 4800 & $\mathrm{~K}$ \\
\hline
\end{tabular}


Regarding the density $\rho$, heat capacity $C$, the thermal conductivity $k$-and, the emissivity $\varepsilon$ definitions and the coefficient $\beta$ definitions, we used the temperature dependence values defined by Gallais et al. in Ref ${ }^{38}$ which are the objects of a dedicated study.

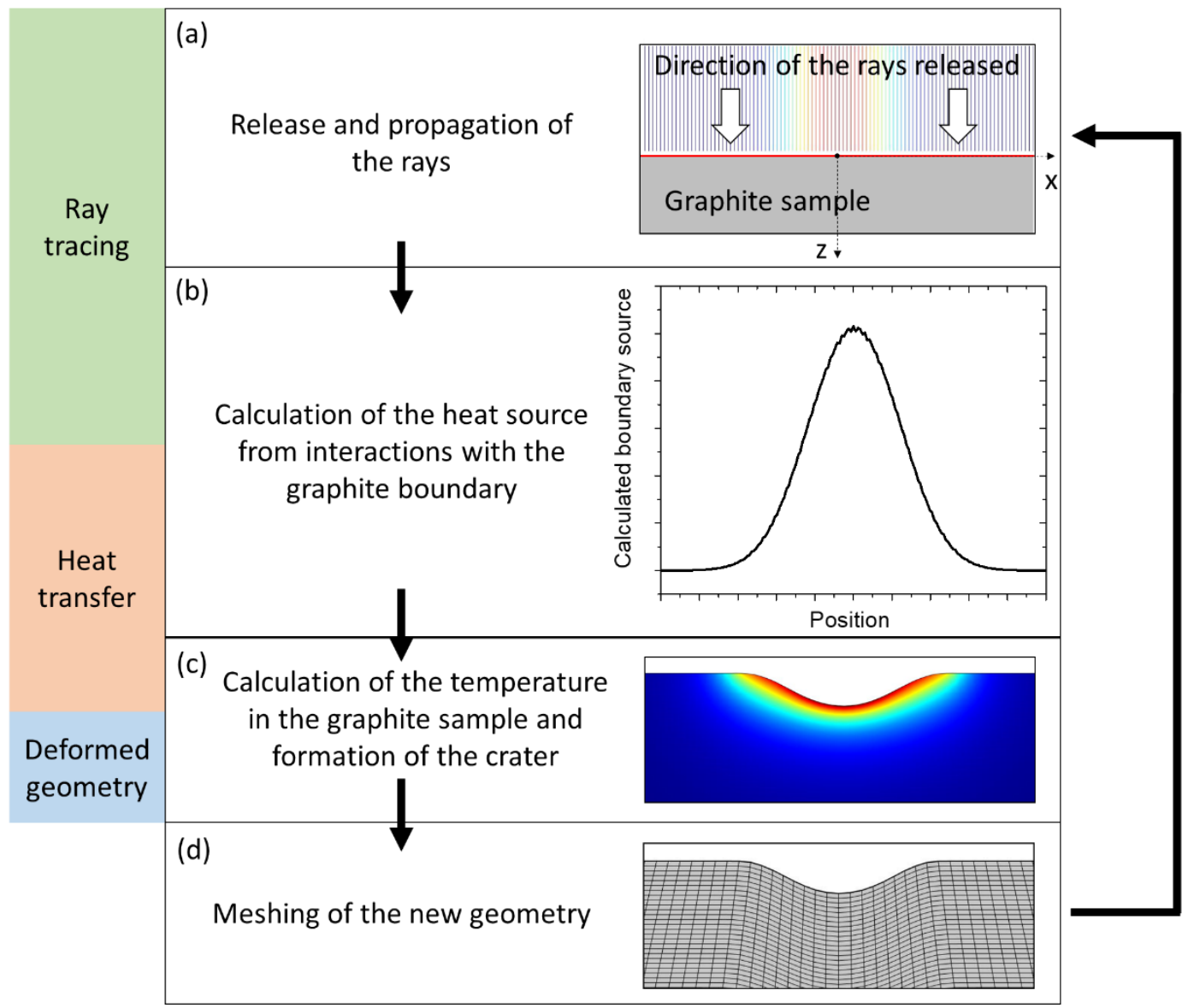

Figure 2 -Simulation method diagram. Each step is described: in the left, the physics module used, in the middle, the detail of the step and in the right, a 2D result example which illustrates the step.

\section{Results and discussion}

\section{a-Single-pulse ablation}

Laser ablation processes depend on physical properties of solid matter, laser parameters and possibly environmental conditions.

Theoretically, in $\mu$ s regime, which is considered for long-pulsed lasers, the absorbed energy from the laser pulse melts the material and heats it to temperature at which the atoms gain sufficient energy to enter into a gaseous state. There is enough time for heat to propagate into the material during the 
pulse. Therefore, in this general case, we observe that evaporation occurs from the liquid state of the material. The molten material is partially ejected from the cavity by the vapour and plasma pressure, but a part of it remains near the surface, held by surface tension forces. After the end of a pulse, the heat quickly dissipates into the bulk of the material and a recast layer is formed ${ }^{45}$.

This general description of laser material interaction has however to be adapted to the case of graphite with a direct transition from solid to vapour at atmospheric pressure. In order to improve the understanding of the laser ablation mechanisms process in graphite, individual ablations were made on a sample using parameters that could be applied for cutting graphite. Pulse laser ablation results in a crater formation on the solid matter surface and the observation and the description of crater is an interesting method to understand the physics of the ablation on the material of interest. We have coupled this experimental study with numerical simulations to improve the understanding of the results.

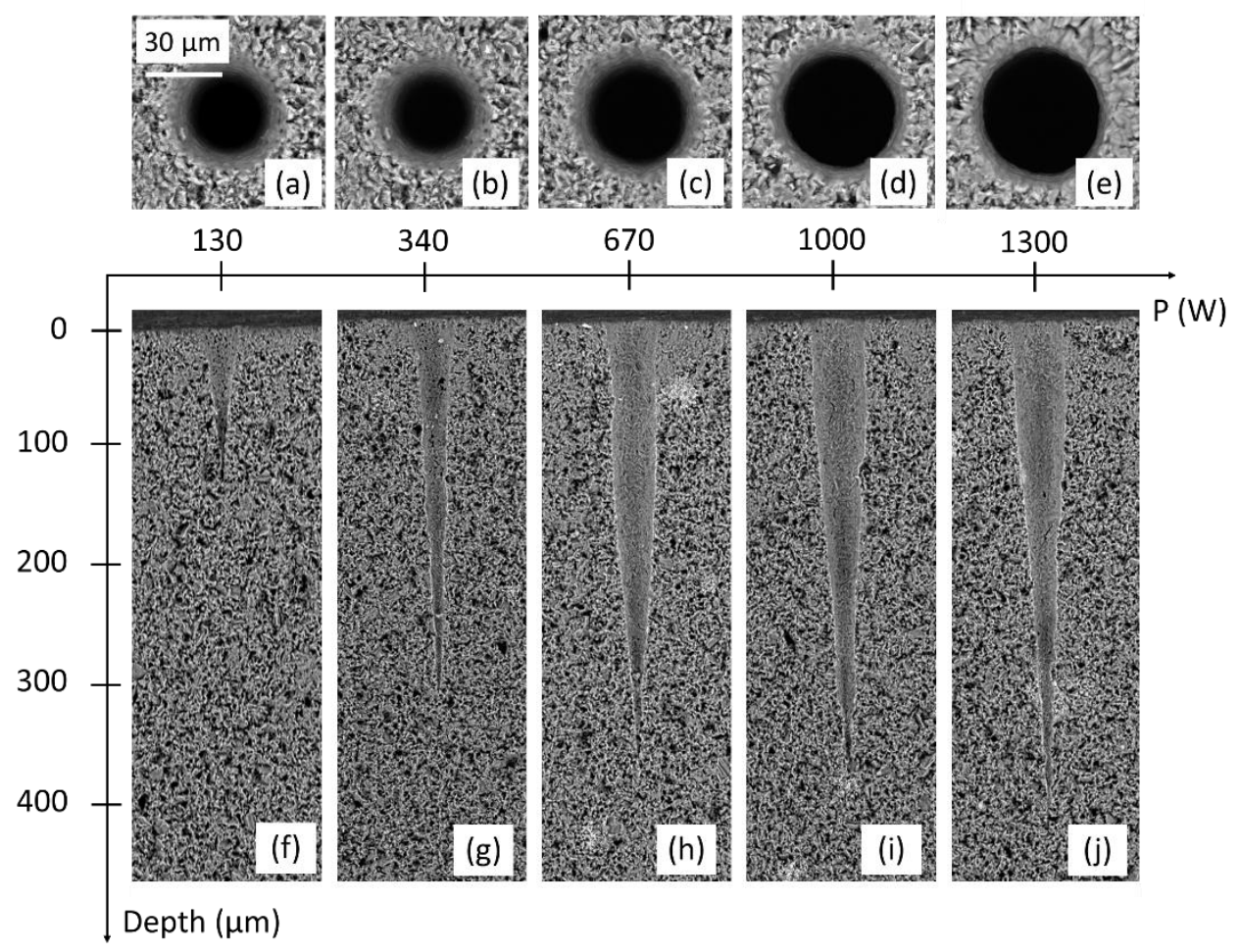

Figure 3 -SEM measurements of craters obtained at different laser powers. (a) to (e) and (f) to (j) are respectively top and cross-sections views. 
Figure 3 shows craters that are produced on graphite by using single-pulse ablation process with increasing laser power, under air. The duration of the laser pulses is $50 \mu \mathrm{s}$. This is the shortest pulse possible time that the laser can produce and we have chosen it to minimize the heat effects.

Figure $3(a)$ to (e) are top views of the holes opening obtained by SEM observations and Figure 3 (f) to (j) are the cross-section views. The cross-sections observations highlight the "channel" shape of the hole. Garnov et al. presented similar results on graphite with $\mu$ s laser ${ }^{36}$. The ablated depth $z_{a b}$ and width $\mathrm{W}_{\mathrm{az}}$ (defined in Sec. II) as a function of laser power applied are represented in Figure 4. The crater diameter varies from $31 \mu \mathrm{m}$ to $44 \mu \mathrm{m}$ and the crater depth from $138 \mu \mathrm{m}$ to $395 \mu \mathrm{m}$. For the highest laser power, that constitutes a high aspect ratio of 9.0 .

The comparison with calculations is presented by the dashed lines on the Figure 4 .

We note that the crater width increases with the laser power to reach a value close to the beam diameter. Considering experimental uncertainties, the calculated crater width (represented by the black dashed line) are close and follows the same trend as the experimental ones.

Regarding the experimental crater depth evolution, it increases with laser power then shows a trend of saturation. The good agreement with experiments is obtained in the lowest power range, leading to crater depth up to $300 \mu \mathrm{m}$. For higher powers, discrepancy is observed. This is probably correlated to a strong material ejection and the formation of a vapour plume which leads a partial screening of the laser power at the sample surface. This phenomenon is not considered in our model and it is certainly a limitation of our approach. However, to take into account the attenuation of the laser resulting from the vapour plume, we could incorporate in the incident laser beam equation an attenuation factor which would depend, for example, on the ablation depth or the laser power. Sinha et $a l .{ }^{46}$ presented a theoretical model which takes into account a residual attenuation of the laser (resulting of the ejected vapour plume). In our case, we can deduce an attenuation factor, for each laser power. It corresponds to the coefficient which should have been multiplied at the laser power to obtain a calculated depth equal to the experimental one. in the entry of the model to obtain the 
experime The numerical values of these factors are indicated in Figure 4 and the corrected depths, considering these attenuation factors, are represented by the red line. It is a simplify postcalculation approach which give perspectives to improve our model and take into account the screening phenomena of the laser power during the calculation.

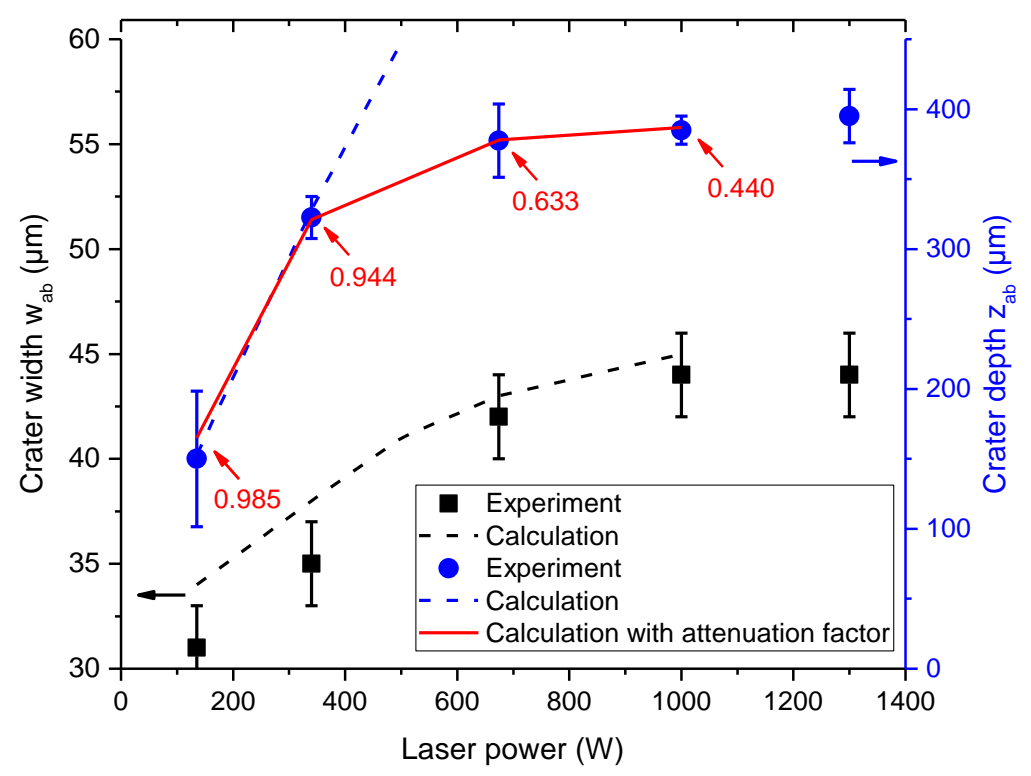

Figure 4 - Experimental crater depth $z_{a b}$ (blue dots) and diameter $w_{a b}$ (black dots) as a function of laser power. The black and blue dashed lines are the corresponding numerical results. The red line indicates the depths obtained with the model considering the attenuation factors (the numerical values are indicated for each power).

The top views (Figure $3(\mathrm{a})$ to (e)) show that the entrance craters are extremely clean and present an excellent definition with very little evidence of collateral thermal effects. It is interesting because for most of materials, microsecond pulses involve many collateral effects that can affect the quality of the structure like a large HAZ, a recast layer, micro-cracks, shock waves surface damages and debris from ejected material ${ }^{37,45,47}$. These observations indicate that micro-second laser drilling technique applied on graphite gives excellent crater quality comparable with that obtained with shorter laser pulses, probably related to the fact that the material directly sublimates. 
The Figure 5 presents the result of the simulations in the case of a laser power of $130 \mathrm{~W}$ during $50 \mu \mathrm{s}$, which corresponds to the experimental crater represented in the Figure 3 (a) and (f). Although, the simulated crater at the end of the irradiation does not have the tapered morphology, we note that dimensions (width and depth) obtained are comparable. The experimental crater morphology, with high-aspect ratio and a tapered shape, is very interesting for graphite cutting or drilling application because it presents high quality cut with limited affected area. The high-aspect ratio of the crater and its tapered shape can be explained by different reasons:

- In our irradiation conditions, the Rayleigh length is $z_{r}=\frac{\pi \omega_{0}^{2}}{\lambda}=1.16 \mathrm{~mm}$, which means that the width of the laser beam increases slowly in the trench of the crater and the divergence of the laser beam should have a slight impact for samples with millimetre thickness.

- As represented on the right part of the Figure 5, the rays, after one reflexion (black rays), which still contain a non-negligible energy (reflection is $8.5+0.5 \%$ ), propagate in the direction of the centre of the hole.

We note that in the Figure 5 we consider the graphite wall as a specular reflection surface. We have studied the case of a scattering diffusion and no changes were found on the results. 

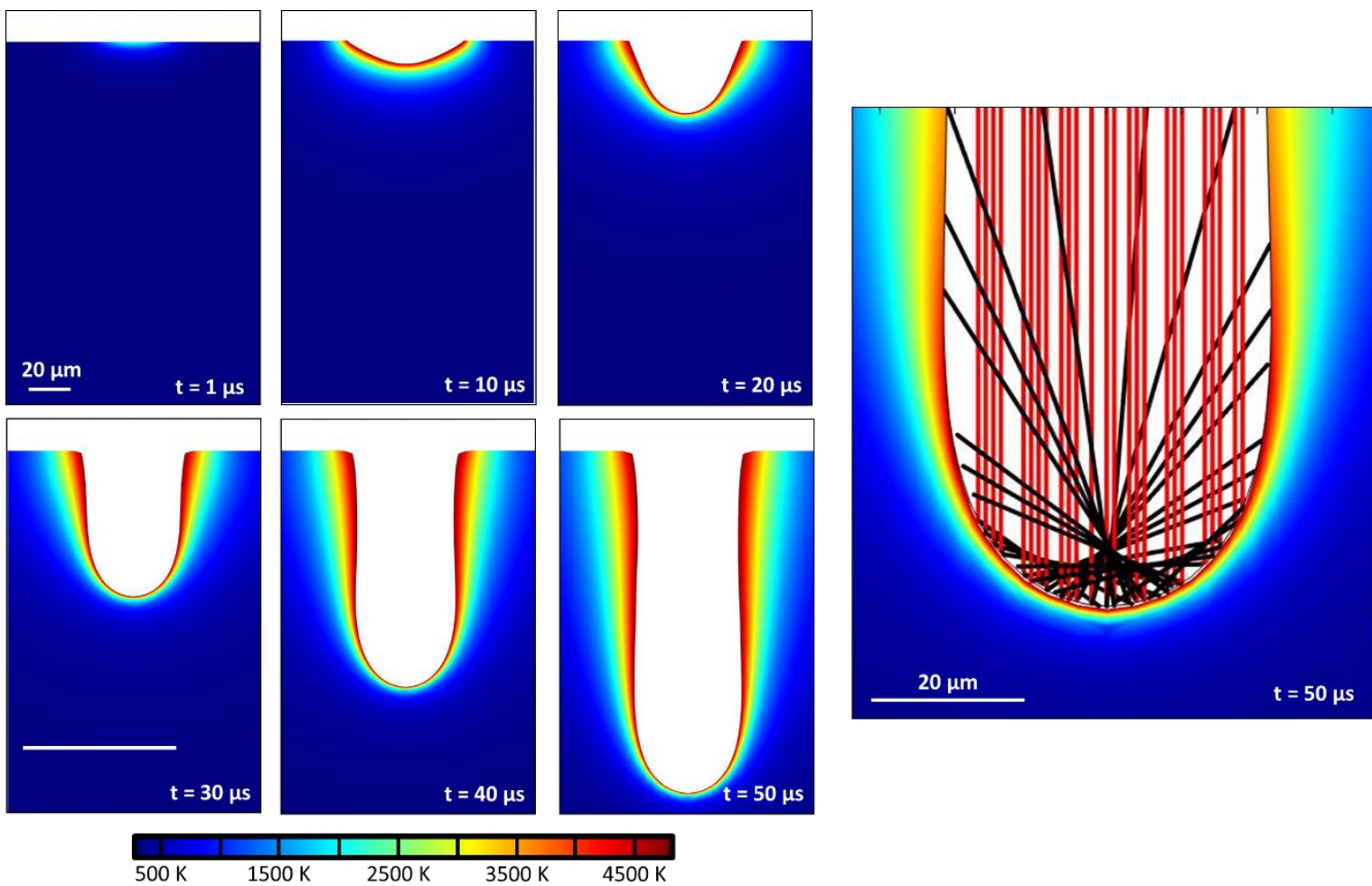

$1500 \mathrm{~K}$

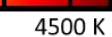

Figure 5 - Simulations of the distribution of temperature, the geometry deformation and the ray propagation in the graphite material at different time (from $1 \mu \mathrm{s}$ to $50 \mu \mathrm{s}$ ) for a laser power of $130 \mathrm{~W}$.

The representation on the right is an enlarged view at $50 \mu \mathrm{s}$ with the rays: the red ones are the no reflected rays and the black ones are the rays reflected once.

\section{b-Application: laser cutting}

Laser cutting is a common manufacturing process used to cut various types of materials. Different parameters like laser power, cutting speed, assist gas pressure, focus point position as well as workpiece material have an impact on the width of the laser cut, quality of the cut edges and operating cost. Based on our previous analysis of single pulse interactions, we propose a laser cutting technique which could be applied for graphite manufacturing.

The cutting process technique developed in our laser facility involves overlapping series of individual craters generated by each pulse. The spot overlap is crucial in laser cutting because it has a direct impact on the cut quality or on the width of laser cut. 


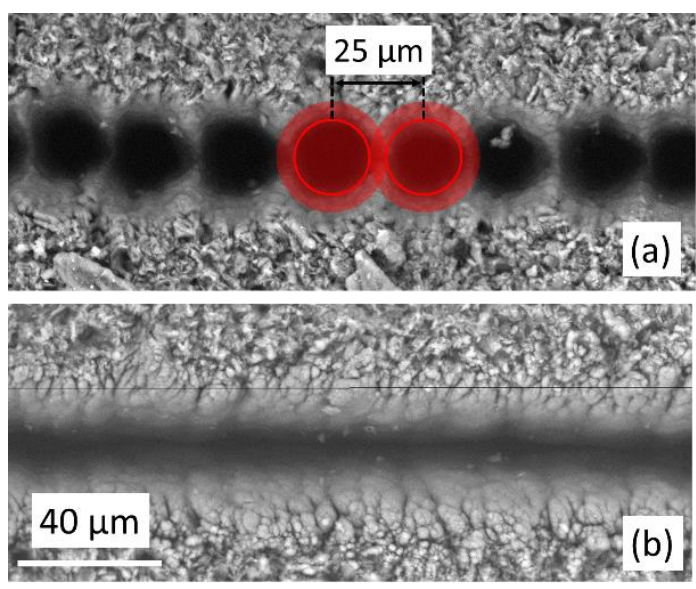

Figure 6-SEM measurements of top-views of a graphite sample illustrating the overlap optimization of craters. (a) and (b) were respectively obtained with laser frequency of $1 \mathrm{kHz}$ and $2.5 \mathrm{kHz}$ and a laser scan speed of $25 \mathrm{~mm} / \mathrm{s}$. A single-pass of the laser was applied.

Figure 6 illustrates the effects of two different spot overlaps on two different lines created in a graphite sample. For both cases, the experimental parameters are: pulse duration $\Delta t=50 \mu$, peak power $P_{\text {peak }}=150 \mathrm{~W}$, laser frequency $f_{\text {rep }}=1 \mathrm{kHz}$ and scan speed $v_{\mathrm{s}}=25 \mathrm{~mm} / \mathrm{s}$. These irradiation conditions give a spot overlap of $37.5 \%$ and an average laser power of $P_{\text {avg }}=6.5 \mathrm{~W}$. The corresponding structure obtained, in Figure 6 (a), presents an inadequate overlap to achieve a complete through-cut in material since bridges of un-cut material remain. A specific parametric study was conducted to optimize the overlapping by increasing the extent of spot overlap in order to obtain the suitable "laser displacement speed/laser frequency" combination which gives the smallest thermal affected area and the highest precision machining kerf (the narrowest and deepest). Figure 6 (b) presents the results obtained with the optimized spot overlap of $93.75 \%$, which corresponds to a distance between two craters of $10 \mu \mathrm{m}$. Based on the results obtained on the individual pulse ablations (presented on Sec. IV 4) and the spot overlapping optimization, we have conducted cutting experiments on $1.5 \mathrm{~mm}$ thick graphite samples. The laser pulse duration was kept to $\Delta \mathrm{t}=50 \mu \mathrm{s}$. Indeed, we obtain with this pulse duration excellent crater quality. To perform graphite cutting, the approach was to increase the laser peak power, from 260 to $1300 \mathrm{~W}$, while keeping the previous defined distance between two craters $(10 \mu \mathrm{m})$ and the 
average power $\left(P_{\text {avg }}=6.5 \mathrm{~W}\right)$. For that, we adjusted for each power $P_{\text {peak }}$ the scan speed $v_{s}$ and laser frequency $f_{\text {rep. }}$ The experimental parameters are summarized in Table 2:

Table 2 - Laser processing parameters

\begin{tabular}{|c|c|c|c|}
\hline Line & $P_{\text {peak }}(\mathrm{W})$ & $f_{\text {rep }}(\mathrm{kHz})$ & $\mathrm{v}_{\mathrm{s}}(\mathrm{mm} / \mathrm{s})$ \\
\hline $\mathrm{a}$ & 260 & 1.25 & 12.5 \\
\hline $\mathrm{b}$ & 390 & 0.833 & 8.34 \\
\hline $\mathrm{c}$ & 650 & 0.5 & 5 \\
\hline $\mathrm{d}$ & 975 & 0.333 & 3.34 \\
\hline $\mathrm{e}$ & 1300 & 0.25 & 2.5 \\
\hline $\mathrm{f}$ & 1300 & 0.25 & 0.25 \\
\hline
\end{tabular}

We have investigated the morphology and the dimensions of the lines with SEM measurements of the cross-section of the sample. Results are presented in Figure 7. 


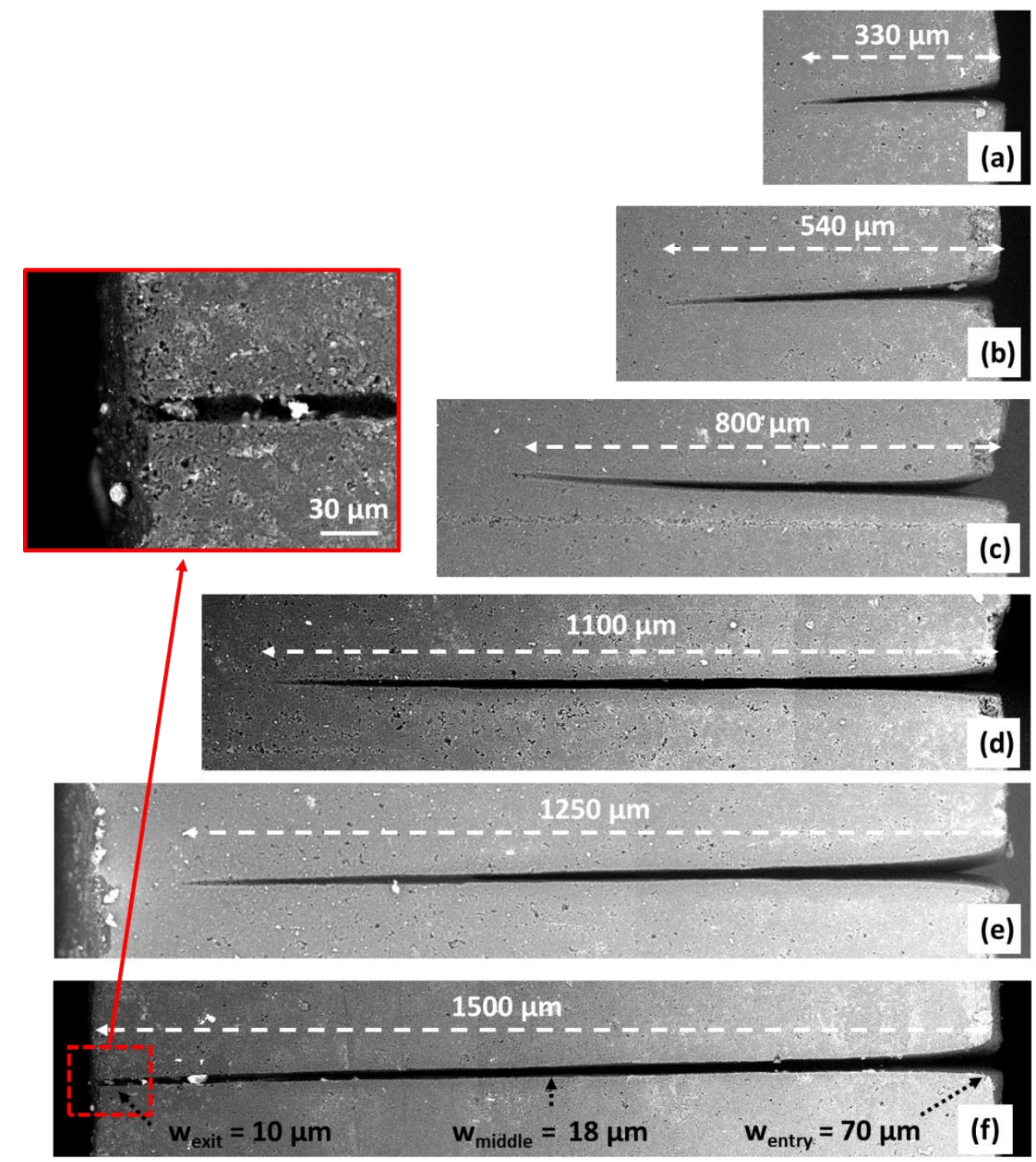

Figure 7-SEM measurements of cross-sections views of the lines formed in the graphite sample with the parameters described in Table 2.

We note that the line depth increases linearly with the applied laser power, as shown in the graph in Figure 8. 


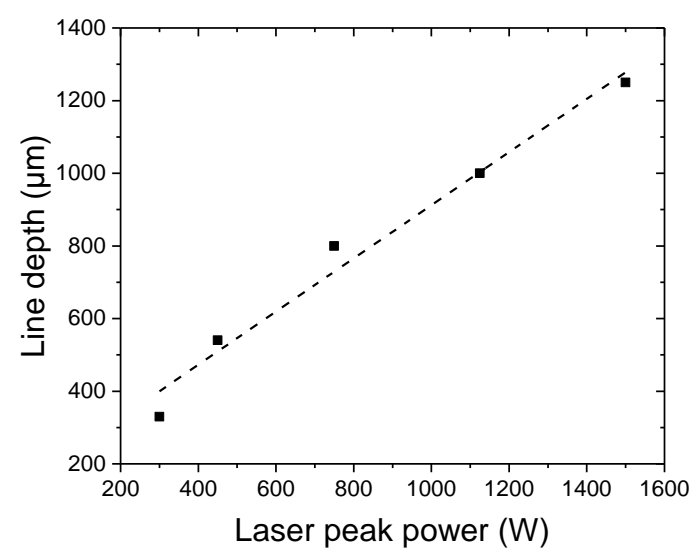

Figure 8 - Line depth as a function of laser peak power

In order to completely cut the graphite sample, with a thickness of $1.5 \mathrm{~mm}$, we have chosen to reduce the scan speed of the processing. We found a scan speed of $0.25 \mathrm{~mm} / \mathrm{s}$ to achieve the cutting of the sample, as shown in Figure 7 (f) (f1) and (f2). In these experimental conditions, the spot overlap was $97.5 \%$. We note that dividing the scan speed by 10 does not affect the kerf width (70 $\mu \mathrm{m}$ ) (Figure 7 (e) and (ft)) and seems to extend slightly the impacted area around the kerf entry width as illustrated in Figure 9. However, this modified area remains moderate and these observations confirm that our cutting laser technique on graphite allows reduced thermal damage and a nearly melt free ablation with high efficiency because it is able to produce depth trench within a short time with excellent cutting quality.
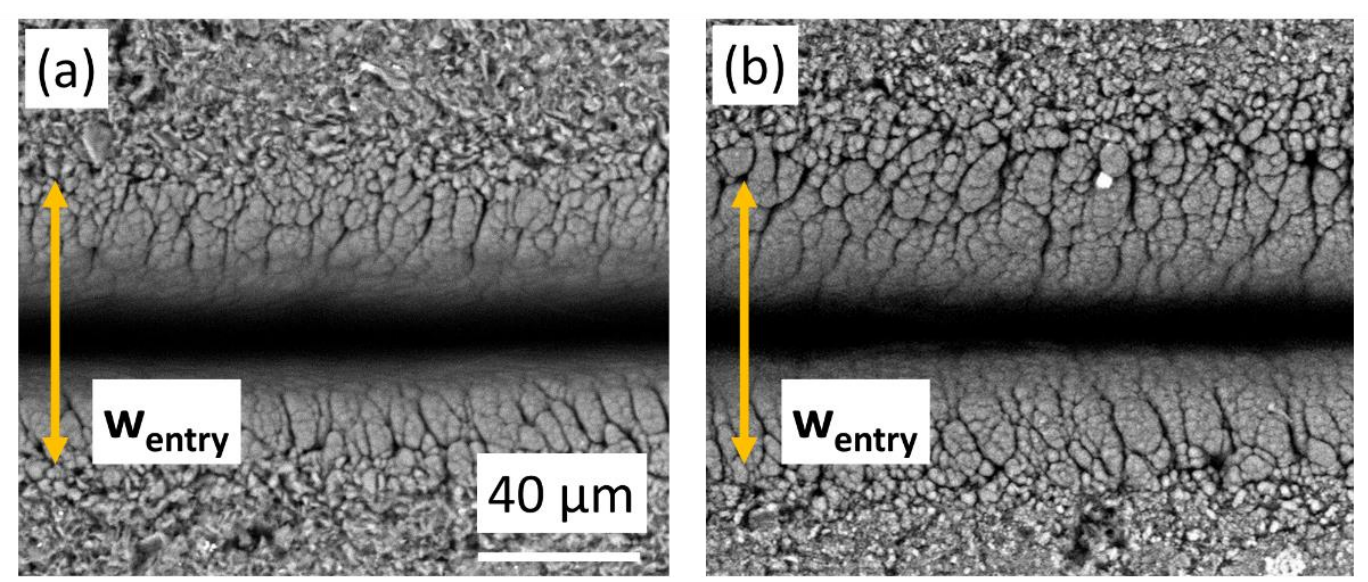

Figure 9-SEM measurements of top-views of trenches illustrating the limited influence of the scan speed on affected area around the kerf entry. (a) and (b) were respectively obtained with scan speeds 
Cutting performances are defined by the affected area, kerf width and cutting depth. The smaller the affected area and the kerf width, the better is the quality of the cut. Therefore, we calculate the tapper angle which is an indicator of the quality of a cut (in drilling or cutting field) and it is defined from the kerf entry $w_{\text {entry }}$ and the exit kerf width $w_{\text {exit }}$ and the thickness $t$ of the sample cut as:

$$
\Theta=\tan ^{-1}\left[\frac{w_{\text {entry }}-w_{\text {exit }}}{2 . t}\right]
$$

We obtain a very small taper angle $\theta$ of 2.1 degrees in the conditions described above.

\section{c-Patterns}

We fabricated high aspect ratio shapes in graphite samples of $1.5 \mathrm{~mm}$ thickness, as represented in Figure 10, with the cutting parameters defined previously. The desired pattern was a narrow trench with a width of $150 \mu \mathrm{m}$ and a depth of $500 \mu \mathrm{m}$ in the $1.5 \mathrm{~mm}$ thickness graphite sample. The top-views SEM observation of the two cutted parts show the proper contour of the cutting in Figure 10 (a) and (b). We note the difference between the width of the two parts: $220 \mu \mathrm{m}-60 \mu \mathrm{m}=160 \mu \mathrm{m}$ which corresponds to the kerf width during the laser cutting.

The cross-section view, on the Figure 10 (c), shows the homogeneity of the trench width throughout the sample thickness. These parts, and particularly the one on Figure 10 (a) demonstrate the capacity of the laser cutting technique to fabricate high aspect ratio parts (here more than 8 ) with a good balance between the relative simplicity of technique implementation and its high cutting speed. For this thickness sample graphite of $1.5 \mathrm{~mm}$, the cutting pattern is realized in around $4.5 \mathrm{~s}$. Regarding the results presented in Figure 7, we can estimate that it would be less than $0.5 \mathrm{~s}$ for a graphite sample of $1 \mathrm{~mm}$ thickness because of the parameters used to obtain the line (e) would be enough for this thickness. 

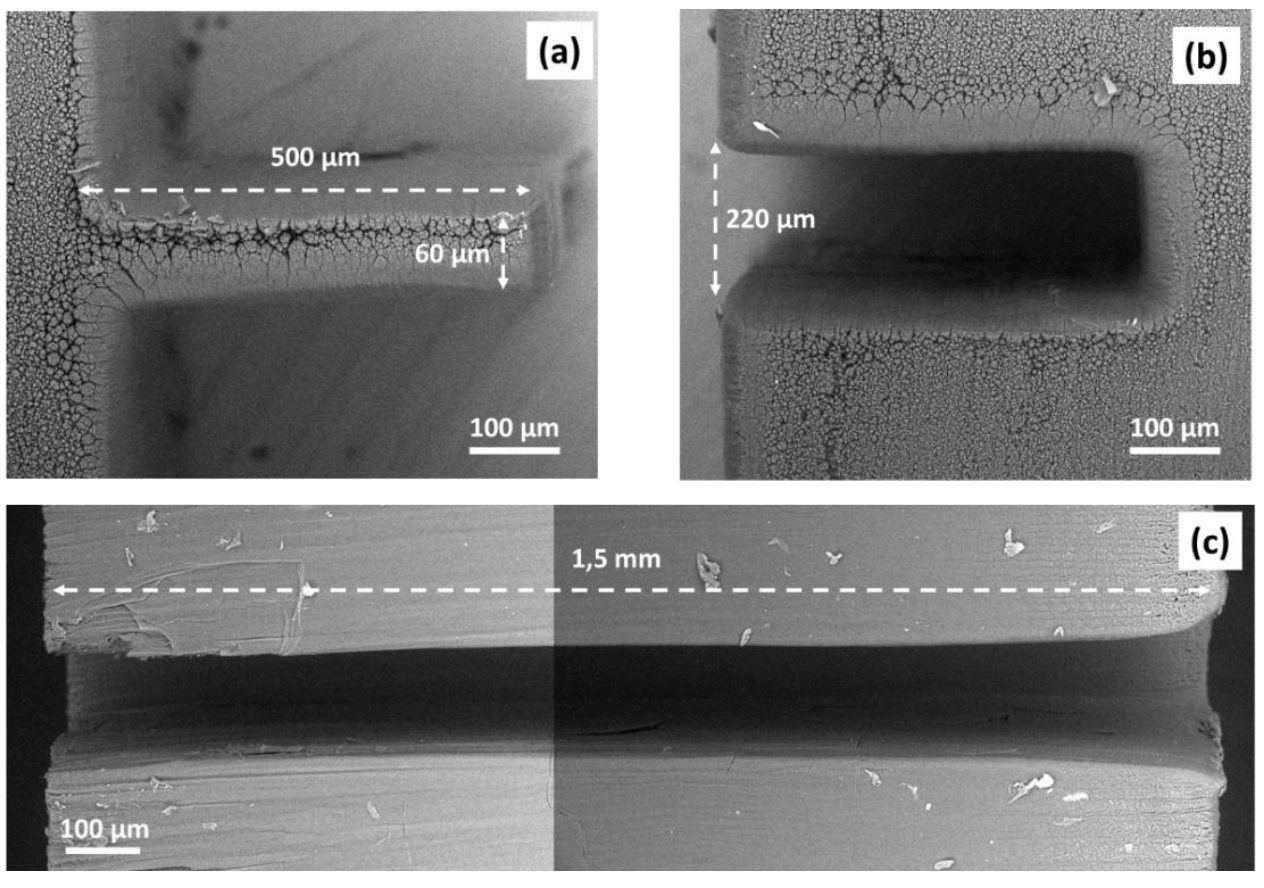

Figure 10-SEM measurements of a pattern. (a) and (b) are top-views and (c) is the corresponding cross-section view of the part observed in (b). The pattern is obtained with a laser power of $1300 \mathrm{~W}, \mathrm{a}$ laser frequency of $0.25 \mathrm{kHz}$ and a laser scan speed of $0.25 \mathrm{~mm} / \mathrm{s}$. A single-pass of the laser was applied.

\section{d-Vacuum influence}

In our experimental setup, it is possible to use a vacuum chamber to carry out laser cutting tests under vacuum atmosphere. To study the influence of the vacuum and compare it with previous results under air, we applied on a graphite sample with a thickness of $800 \mu \mathrm{m}$, similar irradiation parameters as described in Sec. IV 2 (line e of Table 2).

We note comparable quality cutting and no influence of the vacuum was found. Indeed, Figure 11, which is top-view (a) and cross-section view (b) of the graphite sample after cutting, shows that we obtained a narrow trench with a taper angle $\theta$ of 1.4 degrees. Furthermore, the affected area, observed on the top-view, is comparable with that obtained under air and observed in Figure 9 (b). 


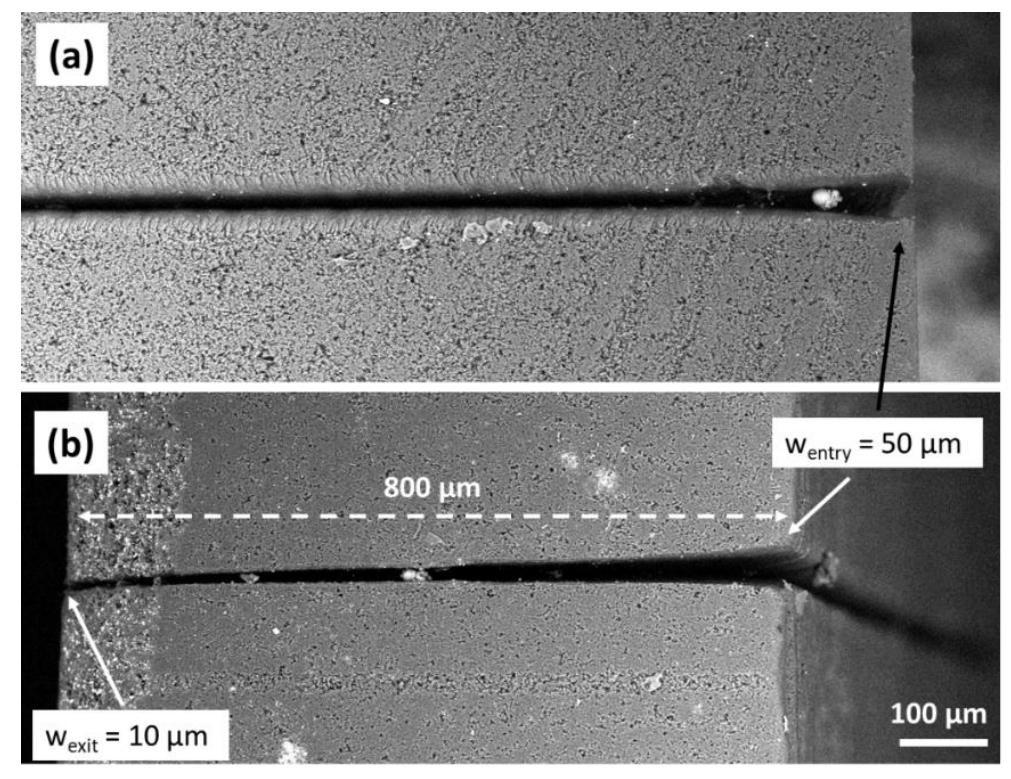

Figure 11 - SEM measurements of the cutting under vacuum of the graphite sample with a thickness

$$
\text { of } 800 \mu \mathrm{m} \text {. }
$$

\section{Conclusion}

Laser micro-processing of graphite employing an Ytterbium fibre laser delivering microsecond pulses at $1080 \mathrm{~nm}$ has been experimentally investigated, with the support of a numerical model to investigate and understand the laser ablation mechanisms processes. Firstly, studies were conducted on singlepulse laser ablations with a minimum pulse duration of $50 \mu \mathrm{s}$ and various power levels up to $1300 \mathrm{~W}$ with a beam diameter of $40 \mu \mathrm{m}$. The crater depth was found to increase firstly linearly with laser power, in good agreement with the simulation results, then followed by a saturation trend that we attribute to the effect of screening by the vapour plume. High aspect ratio craters were obtained, with $400 \mu \mathrm{m}$ depth and $50 \mu \mathrm{m}$ diameter, and excellent crater quality with negligible HAZ that we attribute to the fact that the material directly sublimates. Based on these results, we have applied micro-second laser pulse ablation approach for cutting graphite samples by identifying the best combination of scanning speed and repetition rate (beam overlap) to optimize the cut. We have shown that such laser cutting technique can produce parts with excellent quality (reduced affected area, no recast layer, no micro-cracks and no debris from ejected material) with high efficiency. Production of parts with high 
aspect ratio were demonstrated, with a cutting depth of $1.5 \mathrm{~mm}, 60 \mu \mathrm{m}$ kerf width and $2^{\circ}$ taper angle. Eventually, we have shown that the process can be realized under vacuum, since we have observed comparable quality cutting in such conditions.

From this works on graphite, we consider to transfer this laser ablation technique to nuclear fuels. There are also many potential applications of laser machining of oxide fuels: preparation of samples for heat treatments and the determination of global or local thermophysical properties. This is mainly due to the fact that is has many advantages over conventional techniques: accessible scales, machining precision, etc. However, its implementation remains more difficult. This is why, as part of a first step, we used graphite as model material.

\section{Bibliography}

1. Shirk, M. D. \& Molian, P. A. A review of ultrashort pulsed laser ablation of materials. J. Laser Appl. 10, 18 (1998). https://doi.org/10.2351/1.521827

2. Chichkov, B. N., Momma, C., Nolte, S., von Alvensleben, F. \& Tünnermann, A., Femtosecond, picosecond and nanosecond laser ablation of solids. Appl. Phys. A 63, 109 (1997). http://dx.doi.org/10.1007/BF01567637

3. Dubey, A. K. \& Yadava, V., Laser beam machining-A review. Int. J. Mach. Tools Manuf. 48, 609 (2008). https://doi.org/10.1016/j.ijmachtools.2007.10.017

4. Preuss, S., Demchuk, A. \& Stuke, M. Sub-picosecond UV laser ablation of metals. Appl. Phys. A 61,33 (1995). http://dx.doi.org/10.1007/BF01538207

5. Pronko, P. P., Dutta, S.K., Squier, J., Rudd, J.V., Du, D. \& Mourou, G., Machining of sub-micron holes using a femtosecond laser at 800 nm. Opt. Commun. 114, 106 (1995). https://doi.org/10.1016/0030-4018(94)00585-I.

6. Küper, S. \& Stuke, M., Ablation of polytetrafluoroethylene (Teflon) with femtosecond UV excimer laser pulses. Appl. Phys. Lett. 54, 4 (1989). https://doi.org/10.1063/1.100831

7. Ihlemann, J., Wolff, B. \& Simon, P. Nanosecond and femtosecond excimer laser ablation of fused silica. Appl. Phys. A 45, 363 (1992). http://dx.doi.org/10.1007/BF00324203

8. Ihlemann, J., Scholl, A., Schmidt, H. \& Woltf-Rottke, B. Nanosecond and femtosecond excimer-laser ablation of oxide ceramics. Appl. Phys. A 60, 411 (1995). http://dx.doi.org/10.1007/BF01538343

9. Ashfold, M. N. R., Claeyssens, F., Fuge, G. M. \& Henley, S. J., Pulsed laser ablation and deposition of thin films. Chem Soc Rev 33, 23 (2004). https://doi.org/10.1039/B207644F 
10. Lowndes, D. H., Geohegam, D. B., Puretzky, A. A., Norton, D. P. \& Rouleau, C. M., Synthesis of Novel Thin-Film Materials by Pulsed Laser Deposition Science 273, 898-903 (1996). https://doi.org/10.1126/science.273.5277.898

11. Willmott, P. R. \& Huber, J. R., Pulsed laser vaporization and deposition, Rev. Mod. Phys. 72,315 (2000). https://doi.org/10.1103/RevModPhys.72.315

12. Malinauskas, M., Farsari, M., Piskarskas, A. \& Juodkazis, S., Ultrafast laser nanostructuring of photopolymers: A decade of advances. Phys. Rep. 533, 1 (2013). https://doi.org/10.1016/j.physrep.2013.07.005

13. Phillips, K. C., Gandhi, H. H., Mazur, E. \& Sundaram, S. K. Ultrafast laser processing of materials: a review. Adv. Opt. Photonics 7, 684 (2015). https://doi.org/10.1364/AOP.7.000684

14. Oliveira, V., Ausset, S. \& Vilar, R., Surface micro/nanostructuring of titanium under stationary and non-stationary femtosecond laser irradiation, Appl. Surf. Sci. 255, 7556-7560 (2009). https://doi.org/10.1016/j.apsusc.2009.04.027

15. Her, T. H., Finlay, R. J., Wu, C., Deliwala, S \& Mazur, E., Microstructuring of silicon with femtosecond laser pulses, Appl. Phys. Lett. 73, 1673 (1998). https://doi.org/10.1063/1.122241

16. Xiong, F., Wang, Y. Y. \& Chang, R. P. H. Complex dielectric function of amorphous diamond films deposited by pulsedexcimer-laser ablation of graphite. Phys. Rev. B 48, 8016 (1993). https://doi.org/10.1103/physrevb.48.8016

17. Mechler, Á., Heszler, P., Kántor, Z., Szörényi, T. \& Bor, Z. Excimer laser irradiation induced formation of diamond-like carbon layer on graphite. Appl. Surf. Sci. 138, 174 (1999). https://doi.org/10.1016/S0169-4332(98)00397-3

18. Togashi, H., Aoki, K., Mukaida, M. \& Kameyama, T. Formation of large carbon cluster ions at graphite (HOPG) surfaces by laser irradiation. Appl. Surf. Sci. 96, 276 (1996). https://doi.org/10.1016/0169-4332(95)00431-9

19. Patsalas, P., Kaziannis, S., Kosmidis, C. \& Papadimitriou, D., Optimized pulsed laser deposition by wavelength and static electric field control: The case of tetrahedral amorphous carbon films. J Appl Phys 101, 124903 (2007). https://doi.org/10.1063/1.2745445

20. Collins, C. B., Davanloo, F., Juengermañ, E. M., Jander, D. R. \& Lee, T. J., Preparation and study of laser plasma diamond. Surf. Coat. Technol. 47, 244 (1991). https://doi.org/10.1016/0257-8972(91)90287-7

21. Johnson, S.E., Ashfold, M.N.R., Knapper, M.P., Lade, R.J., Rosser, K.N., Fox, N.A. \& Wang, W.N., Production and characterisation of amorphic diamond films produced by pulsed laser ablation of graphite. Diam. Relat. Mater. 6, 569 (1997). https://doi.org/10.1016/S0925-9635(96)00660-7

22. Cuomo, J. J., Pappas, D. L., Bruley, J., Doyle, J. P. \& Saenger, K. L., Vapor deposition processes for amorphous carbon films with $s p^{3}$ fractions approaching diamond. J. Appl. Phys. 70, 1706 (1991). https://scitation.org/privacy

23. Bower, C., Suzuki, S., Tanigaki, K. \& Zhou, O. Synthesis and structure of pristine and alkali-metal-intercalated singlewalled carbon nanotubes. Appl. Phys. A 67, 47 (1998). https://doi.org/10.1007/s003390050736

24. Rozman, R., Grabec, I. \& Govekar, E., Influence of absorption mechanisms on laser-induced plasma plume. Appl. Surf. Sci. 254, 3295 (2008). https://doi.org/10.1016/j.apsusc.2007.11.029 
25. Thomas, L. D. \& Nesbet, R. K., Low-energy electron scattering by atomic carbon. Phys. Rev. A 12, 2378 (1975). http://dx.doi.org/10.1103/PhysRevA.12.2378

26. Munjal, H. \& Baluja, K. L., Elastic and excitation processes of electron impact on C3 using the R-matrix method. J. Phys. B At. Mol. Opt. Phys. 39, 3185 (2006). https://doi.org/10.1088/0953-4075/39/16/004

27. Halmova, G., Gorfinkiel, J. D. \& Tennyson, J., Low-energy electron collisions with C2 using the R-matrix method. J. Phys. B At. Mol. Opt. Phys. 39, 2849 (2006). https://doi.org/10.1088/0953-4075/39/12/018

28. Hoffman, J., Moscicki, T. \& Szymanski, Z., Acceleration and distribution of laser-ablated carbon ions near the target surface. J. Phys. D: Appl Phys 45, 025201 (2012). https://doi.org/10.1088/0022-3727/45/2/025201

29. Shirk, M. D. \& Molian, P. A., Ultra-short pulsed laser ablation of highly oriented pyrolytic graphite. Carbon 39,1183 (2001). https://doi.org/10.1016/S0008-6223(00)00236-0

30. Hoffman, J., Chrzanowska, J., Kucharski, S., Moscicki, T., Mihailescu, I.N., Ristoscu, C., \& Szymanski, Z., The effect of laser wavelength on the ablation rate of carbon. Appl. Phys. A 117, 395 (2014).

31. Lee, D., Patwa, R., Herfurth, H. \& Mazumder, J., High speed remote laser cutting of electrodes for lithium-ion batteries: Anode. J. Power Sources 240, 368 (2013). https://doi.org/10.1016/j.jpowsour.2012.10.096

32. Lutey, A. H. A., Fortunato, A., Ascari, A., Carmignato, S. \& Orazi, L., Pulsed Laser Ablation of Lithium lon Battery Electrodes. in Volume 2: Processing V002T02A090 (American Society of Mechanical Engineers, 2014). https://doi.org/10.1115/MSEC2014-3967.

33. Schmieder, B. Laser cutting of graphite anodes for automotive lithium-ion secondary batteries: investigations in the edge geometry and heat affected zone. Proceedings Volume 8244, Laser-based Micro- and Nanopackaging and Assembly VI; 82440R (2012). https://doi.org/10.1117/12.912767

34. Luetke, M., Franke, V., Techel, A., Himmer, T., Klotzbach, U., Wetzig, A. \& Beyerab, E., A Comparative Study on Cutting Electrodes for Batteries with Lasers. Phys. Procedia 12, 286-291 (2011). https://doi.org/10.1016/j.phpro.2011.03.135

35. Patwa, R., Herfurth, H., Heinemann, S., Mazumder, J. \& Lee, D., Investigation of different laser cutting strategies for sizing of Li-ion battery electrodes. in International Congress on Applications of Lasers \& Electro-Optics 908 (Laser Institute of America, 2012). https://doi.org/10.2351/1.5062562

36. Habedank, J. B., Endres, J., Schmitz, P., Zaeh, M. F. \& Huber, H. P. Femtosecond laser structuring of graphite anodes for improved lithium-ion batteries: Ablation characteristics and process design. J. Laser Appl. 30, 032205 (2018). https://doi.org/10.2351/1.5040611

37. Garnov, S. V., Konov, V. I., Kononenko, T., Pashinin, V. P. \& Sinyavsky, M. N., Microsecond Laser Material Processing at $1.06 \mu \mathrm{m}$, Laser Physics 14, 910 (2004).

38. Gallais, L., Vidal, T., Lescoute, E., Pontillon, Y. \& Rullier, J.-L., High power continuous wave laser heating of graphite in a high temperature range up to 3800 K, J. Appl. Phys. 129, 043102 (2021). https://doi.org/10.1063/5.0033530 
39. Robin, L., Combis, P., Cormont, P., Gallais, L., Hebert, D., Mainfray, C. \& Rullier, J.-L., Infrared thermometry and interferential microscopy for analysis of crater formation at the surface of fused silica under $\mathrm{CO} 2$ laser irradiation. J. Appl. Phys. 111, 063106 (2012).

40. Cho, W.-I., Naa S.J., Thomy, C. Vollertsen, F., Numerical simulation of molten pool dynamics in high power disk laser welding. J. Mater. Process. Technol. 212, 262 (2012). https://doi.org/10.1016/j.jmatprotec.2011.09.011

41. Cho, J.-H. \& Na, S.-J. Implementation of real-time multiple reflection and Fresnel absorption of laser beam in keyhole. J. Phys.D: Appl. Phys. 39, 5372 (2006). https://doi.org/10.1088/0022-3727/39/24/039

42. Ki, H., Mazumder, J. \& Mohanty, P. S., Modeling of laser keyhole welding: Part I. mathematical modeling, numerical methodology, role of recoil pressure, multiple reflections, and free surface evolution. Metall. Mater. Trans. A 33, 1817 (2002). https://doi.org/10.1007/s11661-002-0190-6

43. Lee, J. Y., Ko, S. H., Farson, D. F. \& Yoo, C. D., Mechanism of keyhole formation and stability in stationary laser welding. J. Phys. D: Appl. Phys. 35, 1570 (2002). https://doi.org/10.1088/0022-3727/35/13/320

44. Otto, A., Koch, H., Leitz, K.-H. \& Schmidt, M., Numerical Simulations - A Versatile Approach for Better Understanding Dynamics in Laser Material Processing. Phys. Procedia 12, 11 (2011). https://doi.org/10.1016/j.phpro.2011.03.003

45. Petkov, P. V., Dimov, S. S., Minev, R. M. \& Pham, D. T. Laser milling: Pulse duration effects on surface integrity. Proc. Inst. Mech. Eng. Part B J. Eng. Manuf. 222, 35 (2008). https://doi.org/10.1243\%2F09544054JEM840

46. Sinha, S., Nanosecond laser ablation of graphite: A thermal model based simulation. J. Laser Appl. 30, 012008 (2018). https://doi.org/10.2351/1.5021520

47. Tu, J., Paleocrassas, A. G., Reeves, N. \& Rajule, N., Experimental characterization of a micro-hole drilling process with short micro-second pulses by a CW single-mode fiber laser. Opt. Lasers Eng. 55, 275-283 (2014) https://doi.org/10.1016/j.optlaseng.2013.11.002 